\title{
Right-sided congenital diaphragmatic hernia masqueraded as right lobar pneumonia in a term newborn infant
}

\author{
Menghao Duan (D) ,' Teo Eu-Leong Harvey James, ${ }^{2,3}$ Suresh Chandran (1) 3,4,5,6
}

${ }^{1}$ Department of Pediatrics, KK Women's and Children's Hospital, Singapore

${ }^{2}$ Department of Diagnostic and Interventional Imaging, KK Women's and Children's Hospital, Singapore

${ }^{3}$ Paediatric Academic Clinical Programme, Duke NUS Medical School, Singapore ${ }^{4}$ Department of Neonatology, KK Women's and Children's Hospital, Singapore ${ }^{5}$ Paediatric Academic Clinical Programme, Lee Kong Chian School of Medicine, Singapore ${ }^{6}$ Paediatric Academic Clinical Programme, Yong Loo Lin School of Medicine, Singapore

\section{Correspondence to} Professor Suresh Chandran: profschandran2019@gmail.com

Accepted 2 October 2021

\section{DESCRIPTION}

A full-term male infant born by normal vaginal delivery developed respiratory distress at $15 \mathrm{~min}$ of life. Antenatal history was unremarkable. The last fetal scan at 32 weeks gestation did not reveal any congenital anomaly. There was no maternal history of leaking liquor, fever, or group B streptococcus colonisation.

Physical examination showed tachypnoea, chest retractions and decreased air entry in the right lung. Oxygen saturation was $80 \%-82 \%$, and blood gas showed respiratory acidosis. He was placed on continuous positive airway pressure of $7 \mathrm{~cm}$ water and $\mathrm{FiO}_{2}$ 0.3. Vital signs were within normal limits. Blood count and $\mathrm{C}$ reactive protein levels were unremarkable. Chest X-ray (CXR) showed opacity in the lower zone of the right chest, suggesting lobar consolidation (figure 1). Antibiotics were initiated promptly. At 6 hours of life, with worsening respiratory distress and echocardiography showing evidence of pulmonary hypertension, he was intubated. Repeat CXR revealed multiple radiolucent bowel loops in the right hemithorax (figure 2), consistent with a diagnosis of right-sided congenital diaphragmatic hernia (R-CDH) as confirmed by ultrasound. Karyotyping was normal.

The infant remained haemodynamically stable while intubated with $\mathrm{FiO}_{2}$ of 0.3 . Surgical repair was performed on day 2 via the transabdominal approach. Intraoperatively, viable loops of intestines were found in the chest and mobilised back into the abdomen. There was no significant liver herniation. The diaphragmatic defect was repaired

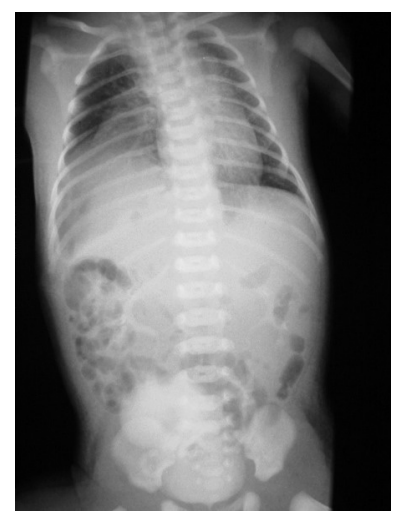

Figure 1 The chest radiograph shows the presence of an opacity in the lower zone of the right chest. Some nonspecific air lucencies are noted in the periphery of the right lower chest.

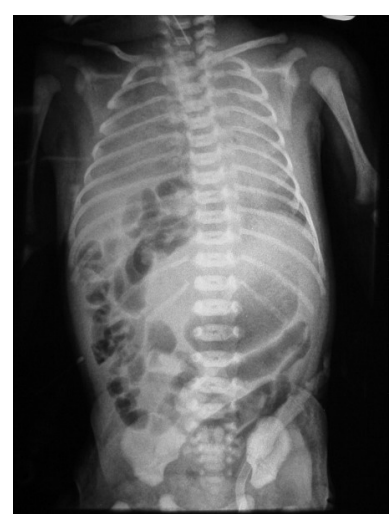

Figure 2 A follow-up chest radiograph at 6 hours of life shows the opacification in the right lung to have increased to involve almost the entire right hemithorax. There are now bowel loops seen in the right lower chest consistent with the diagnosis of a congenital diaphragmatic hernia.

by primary closure. Postoperatively, he was extubated on day 7 , initiated on feeds on day 9, and discharged home on day 17 of life.

Congenital diaphragmatic hernia $(\mathrm{CDH})$ occurs in $0.08-0.45$ per 1000 births, attributed to the failure of fusion of pleuroperitoneal membranes during fetal development. ${ }^{1}$ Antenatal ultrasound screening identifies more than $60 \%$ of $\mathrm{CDH}$ by second trimester and prognosticates using serial lung-to-head ratio assessment and degree of liver herniation. Fetal MRI estimates fetal lung volumes and liver position. ${ }^{2}$

$\mathrm{CDH}$ occurs on the right in only $13 \%$ of cases. ${ }^{3}$ Infants with R-CDH often present with respiratory distress at birth due to lung hypoplasia and persistent pulmonary hypertension of newborn. ${ }^{4}$ Diagnosis of R-CDH can be challenging as clinical presentation and radiological findings may masquerade as lung pathology. ${ }^{5}$ In R-CDH, the liver may obturate the diaphragmatic defect and prevent extrusion of abdominal contents into the thorax, hence not visualised on plain radiographs and delaying diagnosis.

Initial CXRs of R-CDH may be misinterpreted as pneumonia, as demonstrated in our case. Pleural effusion may occur due to hepatic venous outflow obstruction causing congestion. Differentials include pneumatoceles, cystic adenomatoid malformation, congenital lobar emphysema and diaphragmatic eventration. ${ }^{7}$ When diagnosis is equivocal, alternative-imaging modalities such as 
ultrasonography can be complementary. Ultrasound identifies parenchymatous organs and peristaltic movement of bowels in the hemithorax, and the absence of hyperechoic diaphragm and pulmonary A-lines in $\mathrm{CDH}^{8}{ }^{8}$ Doppler vascular flow aids in diagnosing thoracic liver herniation.

Intestinal malrotation is reported in 39\% of infants during initial $\mathrm{CDH}$ repair and those with a missed association have higher risk of future abdominal complications. ${ }^{9}$

Overall survival in R-CDH is approximately $63 \% .^{10}$ The severity of pulmonary hypoplasia and pulmonary hypertension

\section{Patient's perspective}

I work as a paramedic and dealing with life-and-death situations is part of my daily job. However, when my newborn baby became unwell, I felt so helpless. I am very grateful to the doctors for their prompt diagnosis and surgery to ensure my baby had the best outcome.

\section{Learning points}

- Clinical and radiological features of congenital diaphragmatic hernia (CDH) may be misleading at birth and more often suggest other common diagnoses. Delayed diagnosis could lead to increased morbidity and mortality.

- The presence of gas-filled bowels high in the right upper abdominal quadrant migrating through the right subdiaphragmatic plane in the radiogram suggests a diagnosis of R-CDH.

- Use of continuous positive airway pressure respiratory support at birth in undiagnosed CDH could worsen the intrathoracic migration of gut loops. Hence, fetal diagnosis, elective intubation at birth and stabilisation followed by surgical repair are paramount to achieve an optimal outcome. is a significant factor determining $\mathrm{R}-\mathrm{CDH}$ outcome. The timing of surgical repair also contributes to subsequent morbidities. ${ }^{4}$ Fortunately, the initial stabilisation at birth, early diagnosis and surgical intervention gave our patient a favourable outcome.

Contributors MD and SC were involved in the conception and drafting of the manuscript. HT provided interpretation of radiograph findings and input for figure captions. All authors contributed substantially to the article revision.

Funding The authors have not declared a specific grant for this research from any funding agency in the public, commercial or not-for-profit sectors.

Competing interests None declared.

Patient consent for publication Consent obtained from parent(s)/guardian(s)

Provenance and peer review Not commissioned; externally peer reviewed.

\section{ORCID iDs}

Menghao Duan http://orcid.org/0000-0002-6596-7920

Suresh Chandran http://orcid.org/0000-0001-5961-7441

\section{REFERENCES}

1 Langham MR, Kays DW, Ledbetter DJ, et al. Congenital diaphragmatic hernia. epidemiology and outcome. Clin Perinatol 1996;23:671-88.

2 Cordier A-G, Russo FM, Deprest J, et al. Prenatal diagnosis, imaging, and prognosis in congenital diaphragmatic hernia. Semin Perinatol 2020;44:51163.

3 Chandrasekharan PK, Rawat M, Madappa R, et al. Congenital diaphragmatic hernia a review. Matern Health Neonatol Perinatol 2017;3:6.

4 Partridge EA, Peranteau WH, Herkert L, et al. Right- versus left-sided congenital diaphragmatic hernia: a comparative outcomes analysis. J Pediatr Surg 2016:51:900-2.

5 Gupta S, Warrell D, Smith L, et al. Strangulated right-sided diaphragmatic hernia presenting and treated as lung empyema: beware of the differential diagnosis. BMJ Case Rep 2020;13. doi:10.1136/bcr-2019-233440. [Epub ahead of print: $08 \mathrm{Jul}$ 2020].

6 Kirchner SG, Burko H, O'Neill JA, et al. Delayed radiographic presentation of congenital right diaphragmatic hernia. Radiology 1975;115:155-6.

7 Gleeson F, Spitz L. Pitfalls in the diagnosis of congenital diaphragmatic hernia. Arch Dis Child 1991;66:670-1.

8 Corsini I, Parri N, Coviello C, et al. Lung ultrasound findings in congenital diaphragmatic hernia. Eur J Pediatr 2019;178:491-5.

9 Heiwegen $\mathrm{K}$, de Blaauw I, van Ling J, et al. Malrotation in congenital diaphragmatic hernia: is it really a problem? Eur J Pediatr Surg 2020;30:434-9.

10 Victoria T, Danzer E, Oliver ER, et al. Right congenital diaphragmatic hernias: is there a correlation between prenatal lung volume and postnatal survival, as in isolated left diaphragmatic hernias? Fetal Diagn Ther 2018;43:12-18.

Copyright 2021 BMJ Publishing Group. All rights reserved. For permission to reuse any of this content visit

https://www.bmj.com/company/products-services/rights-and-licensing/permissions/

BMJ Case Report Fellows may re-use this article for personal use and teaching without any further permission.

Become a Fellow of BMJ Case Reports today and you can:

- Submit as many cases as you like

- Enjoy fast sympathetic peer review and rapid publication of accepted articles

- Access all the published articles

Re-use any of the published material for personal use and teaching without further permission

Customer Service

If you have any further queries about your subscription, please contact our customer services team on +44 (0) 2071111105 or via email at support@bmj.com.

Visit casereports.bmj.com for more articles like this and to become a Fellow 